\title{
Low expression of KCNN3 may affect drug resistance in ovarian cancer
}

\author{
XIA LIU ${ }^{1}$, LUWEI WEI ${ }^{2}$, BINGBING ZHAO $^{2}$, XIANGXUE CAI $^{1,3}$, CAIHUA DONG $^{1}$ and FUQIANG YIN ${ }^{3,4}$ \\ ${ }^{1}$ Key Laboratory of Longevity and Ageing-Related Disease of Chinese Ministry of Education, Centre for Translational Medicine \\ and School of Preclinical Medicine; ${ }^{2}$ Department of Gynecologic Oncology, The Affiliated Tumor Hospital; \\ ${ }^{3}$ Life Sciences Institute; ${ }^{4}$ Key Laboratory of High-Incidence Tumor Prevention and Treatment, Ministry of Education, \\ Guangxi Medical University, Nanning, Guangxi 530021, P.R. China
}

Received December 6, 2017; Accepted April 26, 2018

DOI: $10.3892 / \mathrm{mmr} .2018 .9107$

\begin{abstract}
Drug resistance is a principal contributor to the poor prognosis of ovarian cancer (OC). Therefore, identifying factors that affect drug resistance in OC is critical. In the present study, 51 OC specimens from lab collections were immunohistochemically tested, public data for 489 samples from The Cancer Genome Atlas cohort and 1,656 samples from the Kaplan-Meier Plotter were downloaded, and data were retrieved from Oncomine. It was identified that the mRNA and protein expression of the potassium calcium-activated channel subfamily $\mathrm{N}$ member 3 (KCNN3) was markedly lower in OC tissues compared with normal tissues, and in drug-resistant OC tissues compared with sensitive OC tissues. Low KCNN3 expression consistently predicted shorter disease-free and overall survival (OS). Specifically, low KCNN3 expression predicted shorter OS in 395 patients with low expression levels of mucin-16. There was additional evidence that KCNN3 expression is mediated by microRNA-892b. Furthermore, text mining and analyses of protein and gene interactions indicated that KCNN3 affects drug resistance. To the best of the authors' knowledge, this is the first report to associate KCNN3 with poor prognosis and drug resistance in OC. The present findings indicated that $\mathrm{KCNN} 3$ is a potential prognostic marker and therapeutic target for $\mathrm{OC}$.
\end{abstract}

\section{Introduction}

Ovarian cancer (OC) is a principal cause of cancer mortality in women, with an estimated 14,080 cases of mortality in the USA (1) every year, and 22,500 cases of mortality annually in China (2). Although patients with OC are initially responsive

Correspondence to: Dr Fuqiang Yin, Life Sciences Institute, Guangxi Medical University, 22 Shuangyong Road, Nanning, Guangxi 530021, P.R. China

E-mail: yinfq@mail2.sysu.edu.cn

Key words: potassium calcium-activated channel subfamily $\mathrm{N}$ member 3, ovarian cancer, prognosis, drug resistance to standard therapy (generally debulking surgery followed by platinum-centered chemotherapy) (3), 70\% of them develop recurrent disease (4). The 5-year overall survival (OS) is very poor as the relapsed disease is frequently incurable (5), with little improvement over the last 30 years (6). The emergence of a drug-resistant disease is thus a primary obstacle in the clinical management of OC. To overcome these unsatisfactory treatment outcomes, understanding the molecular mechanisms that contribute to drug resistance and identifying predictive biomarkers are critical (7).

Accumulating evidence indicates that ion channels serve crucial roles in cancer biology $(8,9)$ and mediate numerous aspects of cancer pathology, including apoptosis, angiogenesis, cell growth, migration, invasion and metastasis (10). Among the ion channels, potassium channels are the most diverse and ubiquitous, and represent easily accessible cancer biomarkers and targets for therapy $(11,12)$. In OC, potassium channels have been demonstrated to be closely associated with cancer progression and outcomes. Potassium two pore domain channel subfamily $\mathrm{K}$ member 9 is involved in the oncogenesis of $\mathrm{OC}$, although its prominent expression is paradoxically associated with better survival (13); potassium voltage-gated channel subfamily $\mathrm{H}(\mathrm{KCNH})$ member 1 and $\mathrm{KCNH}$ member 2 (KCNH2) expression is associated with poor prognosis $(14,15)$, and $\mathrm{KCNH} 2$ channel activity is associated with tumor drug resistance (16).

Potassium calcium-activated channel subfamily $\mathrm{N}$ member 3 (KCNN3), a potassium channel of the small conductance $\mathrm{Ca}^{2+}$-activated potassium channel family (17), contributes to the development and progression of numerous solid tumors. In melanoma cells, upregulation of KCNN3 enhances cell motility by hyperpolarizing the cell membrane potential (18); in breast cancer cells, $\mathrm{KCNN} 3$ is a mediator of cell migration (19), and together with $\mathrm{P} 2 \mathrm{X}$ purinoceptor 7 , contributes to cysteine cathepsin-dependent cell invasiveness (20); and in colon cancer, KCNN3, together with short transient receptor potential channel 1 (TRPC1) and calcium release-activated calcium channel protein 1 (orai-1), regulates store operated calcium entry (SOCE)-dependent cell migration (21). Furthermore, KCNN3 is upregulated by a 16 -fold change in bortezomib-resistant BN myeloma cells (22), which suggests that its expression is associated with drug resistance. 
However, KCNN3 has not been widely studied with respect to cancer, and research on its role in $\mathrm{OC}$ is rare. To the best of the authors' knowledge, the present study, which used public data, bioinformatics and immunohistochemistry analyses, is the first to report the association of KCNN3 with prognosis and drug resistance in $\mathrm{OC}$.

\section{Materials and methods}

Data acquisition. Data regarding gene expression determined using $\log 2$ median-centered intensity in OC and normal controls were retrieved from microarrays downloaded from The Cancer Genome Atlas (TCGA) Ovarian cohort, including 586 ovarian serous adenocarcinoma and 8 normal control samples; and the Yoshihara Ovarian cohort, including 43 ovarian serous adenocarcinoma and 10 normal control samples, deposited in Oncomine (https://www.oncomine.org/resource/main. html) $(23,24)$ ) (Tables I and II). The mRNA expression values of 489 tissues from a total of 586 patient samples with ovarian serous adenocarcinoma were determined via Agilent microarray analysis (Agilent Technologies, Inc., Santa Clara, CA, USA) (25), and these data were downloaded from the cBioportal (http://www.cbioportal.org/) (26,27). Corresponding data of microRNA (miR), DNA methylation and clinical data of the 489 OC tissues were also downloaded from cBioportal (http://www.cbioportal.org/). Among the 489 tissues, 197 were platinum-sensitive and 90 were resistant tissues. KCNN3 mRNA expression (probe: 205903_s_at) data and survival information of the 1,656 patients with OC [including 395 patients with OC who had low cancer antigen (CA) 125 expression levels] were downloaded from the KM Plotter (http://kmplot.com/), which is a collection of 14 independent microarrays (data set nos. GSE14764, GSE15622, GSE18520, GSE19829, GSE23554, GSE26193, GSE26712, GSE27651, GSE30161, GSE3149, GSE51373, GSE63885, GSE65986 and GSE9891) from the Gene Expression Omnibus (GEO) profiles and TCGA ovarian cohort (28). No alterations were made to any of the aforementioned data used in the analysis.

Samples. OC specimens were collected from adult patients (aged 18-87 years old) with ovarian serous adenocarcinoma who were treated at The Affiliated Tumor Hospital of Guangxi Medical University (Nanning, China) between April 2005 and December 2012. All patients underwent optimal cytoreductive surgeries (residual $<2 \mathrm{~cm}$ ), and at least six cycles of platinum-paclitaxel chemotherapy following surgery. The classification of response to chemotherapy was defined as sensitive (complete remission and relapse $>6$ months following stopping chemotherapy; $\mathrm{n}=27$ ) or resistant (complete remission and relapse $<6$ months following stopping chemotherapy; $n=24$ ) to primary chemotherapy. Specimens were fixed in $10 \%$ formalin for $48 \mathrm{~h}$ at room temperature and then embedded in paraffin. Paraffin-embedded sections $(4 \mu \mathrm{m})$ from 51 patients (aged 26-71 years old; median age, 49 years old) were subsequently stained with $0.5 \%$ hematoxylin for $8 \mathrm{~min}$ at room temperature and $0.5 \%$ eosin for $1 \mathrm{~min}$ at room temperature (H\&E), and the stained sections were evaluated by two independent pathologists. The present study was approved by The Ethics Committee of Guangxi Medical University and was performed in accordance with The Declaration of Helsinki. Informed consent was obtained from all individual participants included in the present study. Furthermore, commercially available adult human normal tissue arrays were purchased from Cybrdi, Inc. (Rockville, MD, USA; cat. no. OV241c), consisting of six OC tissues and six adjacent normal ovarian tissues. H\&E staining on these tissues was performed prior to purchase by Cybridi, Inc. In total, six normal ovarian tissues and 57 OC tissues were included in the present study.

Immunohistochemistry. The primary antibody used in the present study was rabbit monoclonal antibody against human KCNN3 (1:1,000; Abcam, Cambridge, UK; cat. no. ab192515), and the secondary antibody was goat anti-rabbit immunoglobulin $\mathrm{G}$ heavy and light chains (horseradish peroxidase; 1:2,000; Abcam; cat. no. ab97051). The sections was incubated with $3 \%$ peroxidase blocking solution (SPlink Detection kits, OriGene Technologies, Inc., Beijing, China; cat. no. SP-9000) for $15 \mathrm{~min}$ at room temperature, and then incubated with $10 \%$ goat serum (SPlink Detection kits; OriGene Technologies, Inc.; cat. no. SP-9000) for $15 \mathrm{~min}$ at room temperature. Subsequently, the sections were incubated with primary antibody in $0.01 \mathrm{M}$ PBS for $12 \mathrm{~h}$ at $4^{\circ} \mathrm{C}$, and then incubated with secondary antibody for $1 \mathrm{~h}$ at room temperature. The slides were imaged using an EVOS FL Auto Imaging System (Life Technologies; Thermo Fisher Scientific, Inc., Waltham, MA, USA; magnification, x10 and x40). All slides were evaluated independently by two pathologists. Slide immunostaining was scored based on the percentage and intensity of the stained tumor cells (29). The intensity of immunostaining was graded as following: 0 , negative staining; $1+$, weak staining; $2+$, moderate staining; and $3+$, strong staining. The staining percentage was graded as following: 0, stained tumor cells $<25 \%$; 1+, stained tumor cells $25-50 \%$; 2+, stained tumor cells $50-75 \%$; and $3+$, stained tumor cells $>75 \%$. The final immunostaining score was calculated by multiplying the staining intensity score by the staining percentage score. Final values ranged between 0 and 9 . Scores $<5$ were considered 'low expression' and scores $\geq 5$ were considered 'high expression'.

Bioinformatics analysis. Biological process annotation was performed using Coremine Medical (http://www.coremine. $\mathrm{com} / \mathrm{medical} /$ ) (30). A protein-gene interaction network was generated using GeneMania (http://www.genemania. org/) (31,32). miR-mRNA predictions used miRsystem, which has seven prediction tools, including TARGETSCAN, RNA22, PICTAR, DIANA, MIRANDA, MIRBRIDGE and PITA (http://mirsystem.cgm.ntu.edu.tw/) (33).

Statistical analysis. The data were analyzed using SPSS 20.0 software (IBM Corp., Armonk, NY, USA). Gene mRNA expression levels are presented as the mean \pm standard deviation. Homogeneity of variance was analyzed using the Student's t-test. Correlations between gene-protein expression and clinicopathological factors were evaluated using the Pearson's $\chi^{2}$ test and Spearman's correlation (2-sided). The probability of survival and significance was calculated using the Kaplan-Meier method. Gene expression values were dichotomized into high and low expression, using the median as a cut-off in all the above analyses (34). Correlations between miRs/DNA methylation and gene expression were analyzed 


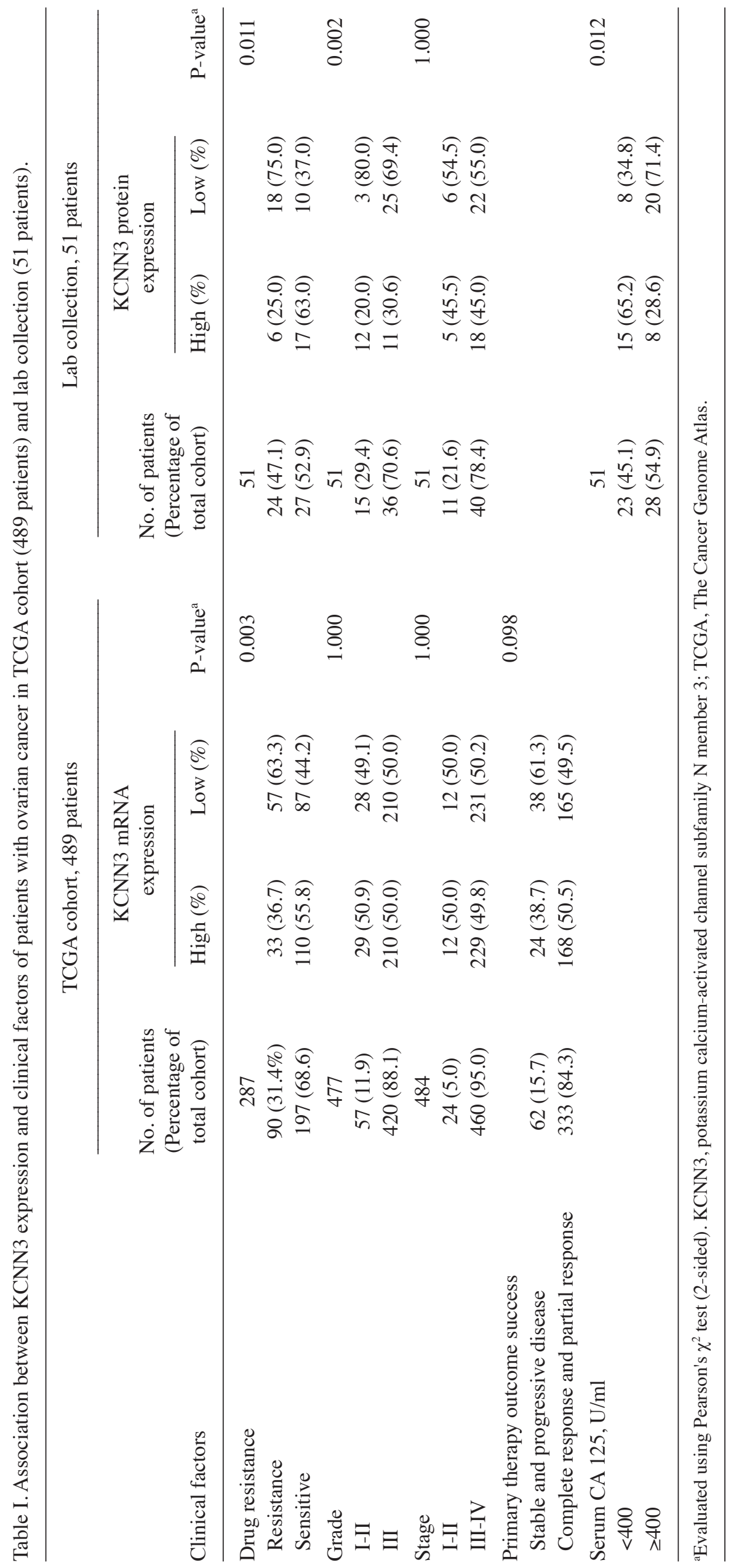


Table II. On the basis of the microarray data retrieved from Oncomine, KCNN3 is differentially expressed and downregulated in the majority of tumor types.

\begin{tabular}{|c|c|c|c|}
\hline \multirow[b]{2}{*}{$\begin{array}{l}\text { Cancer } \\
\text { type }\end{array}$} & \multicolumn{3}{|c|}{ Datasets $^{\mathrm{a}}$} \\
\hline & All & $\begin{array}{c}\text { KCNN3 } \\
\text { upregulated }\end{array}$ & $\begin{array}{c}\text { KCNN3 } \\
\text { downregulated }\end{array}$ \\
\hline Bladder & 6 & & 2 \\
\hline $\begin{array}{l}\text { Brain and central } \\
\text { nervous system }\end{array}$ & 13 & 3 & 1 \\
\hline Breast & 10 & & 1 \\
\hline Cervical & 6 & - & - \\
\hline Colorectal & 11 & & 1 \\
\hline Esophageal & 7 & - & - \\
\hline Gastric & 6 & & 1 \\
\hline Head and neck cancer & 18 & - & - \\
\hline Kidney & 7 & & 1 \\
\hline Leukemia & 14 & & 1 \\
\hline Liver & 8 & - & - \\
\hline Lung & 13 & - & - \\
\hline Lymphoma & 11 & & 1 \\
\hline Melanoma & 5 & - & - \\
\hline Myeloma & 4 & 1 & \\
\hline Ovarian & 8 & & 2 \\
\hline Pancreatic & 9 & 1 & 2 \\
\hline Prostate & 15 & - & - \\
\hline Sarcoma & 6 & & 2 \\
\hline Other & 14 & & 2 \\
\hline Sum & 191 & 5 & 17 \\
\hline
\end{tabular}

'Datasets deposited in Oncomine. $\mathrm{P}<0.05$, fold change $\geq 2.0$. '-' indicates that no significant change was detected; KCNN3, potassium calcium-activated channel subfamily $\mathrm{N}$ member 3 .

using bivariate correlations. $\mathrm{P}<0.05$ was considered to indicate a statistically significant difference.

\section{Results}

KCNN3 expression is decreased in OC tissues and drug-resistant tissues compared with normal tissues. KCNN3 expression was significantly decreased in OC tissues compared with the normal control, according to the TCGA Ovarian cohort and Yoshihara Ovarian cohort deposited in Oncomine. (Fig. 1A and B). KCNN3 mRNA was significantly lower in 586 samples ovarian serous cystadenocarcinomas compared with eight normal ovaries, by 2.770-fold change obtained from the TCGA Ovarian cohort, as determined via Log2 median-centered intensity (Fig. 1A); and was lower in 40 ovarian serous cystadenocarcinomas compared with 10 normal peritoneal samples, by 5.778 -fold changes, according to the Yoshihara Ovarian cohort (Fig. 1B). Furthermore, KCNN3 was significantly lower in drug-resistant OC tissues compared with sensitive tissues. KCNN3 mRNA expression in 90 platinum-resistant tissues was significantly
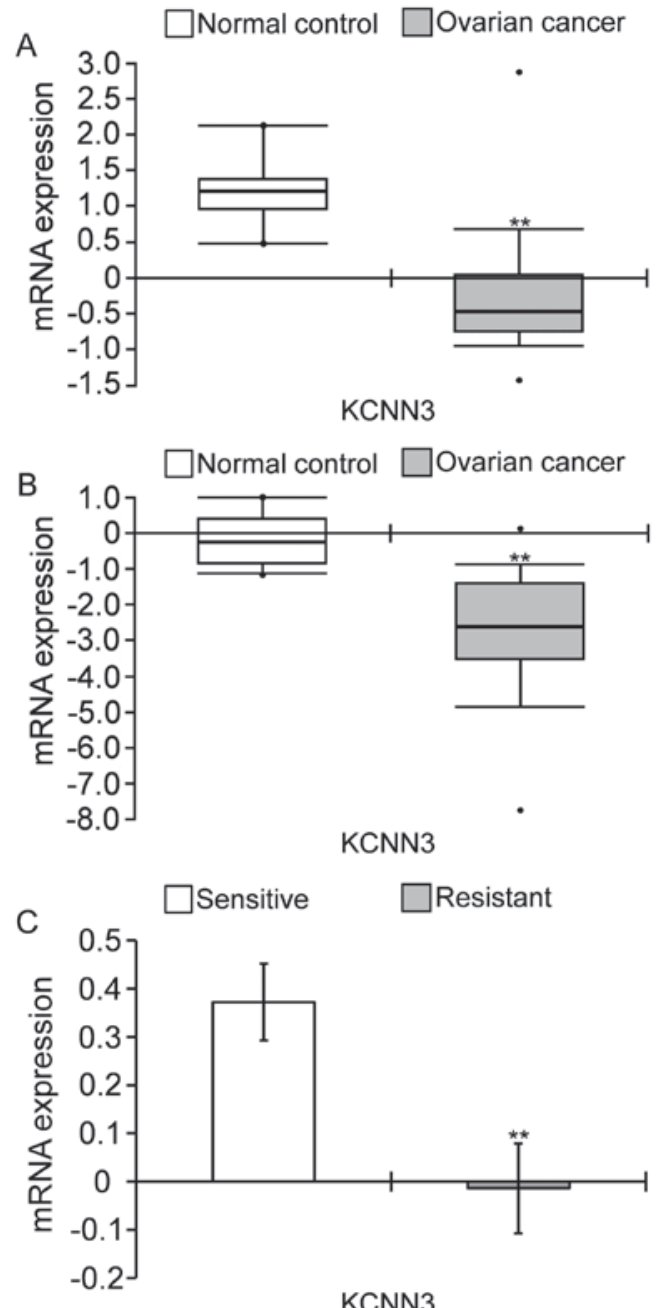

Figure 1. KCNN3 expression is lower in OC tissues compared with normal controls, and in drug-resistant $\mathrm{OC}$ tissues compared with sensitive tissues, according to microarray analysis. (A) KCNN3 was significantly decreased in 586 ovarian serous cystadenocarcinomas compared with eight normal ovaries (TCGA ovarian cohort; $\mathrm{P}=0.0000275$ ). (B) KCNN3 was significantly decreased in 40 ovarian serous cystadenocarcinomas compared with 10 peritoneal samples (Yoshihara ovarian analysis; $\mathrm{P}=0.00000000656$ ). Gene expression in the analyses was determined using Log2 median-centered intensity in Oncomine. (C) Average $\mathrm{KCNN} 3$ expression was lower in 90 platinum-resistant OC tissues compared with 197 sensitive tissues (TCGA ovarian cohort downloaded from cBioportal). ${ }^{* *} \mathrm{P}<0.01$ vs. sensitive tissues. KCNN3, potassium calcium-activated channel subfamily $\mathrm{N}$ member 3; OC, ovarian cancer; TCGA, The Cancer Genome Atlas.

lower compared with in 197 platinum-sensitive tissues in TCGA cohort (Fig. 1C; P<0.01; Table I).

The morphology of $57 \mathrm{OC}$ tissues and 6 normal ovarian tissues were investigated via $H \& E$ staining (Fig. 2). The immunohistochemistry results of these tissues demonstrated that the majority of $\mathrm{OC}$ tissues revealed low expression levels of KCNN3 (33/57 cases); whereas, all six normal controls revealed high expression levels of the protein (Fig. 2). Statistical analysis using the $\chi^{2}$ test revealed a significant low expression of $\mathrm{KCNN} 3$ in $\mathrm{OC}$ tissues, as determined via imaging of immunohistochemistry results $(\mathrm{P}=0.009)$. Furthermore, among the 51 OC specimens from the lab collection, KCNN3 protein expression was significantly lower in 24 drug-resistant OC tissues compared with 27 sensitive tissues, as determined via imaging of immunohistochemistry results (Fig. 2; Table I; 


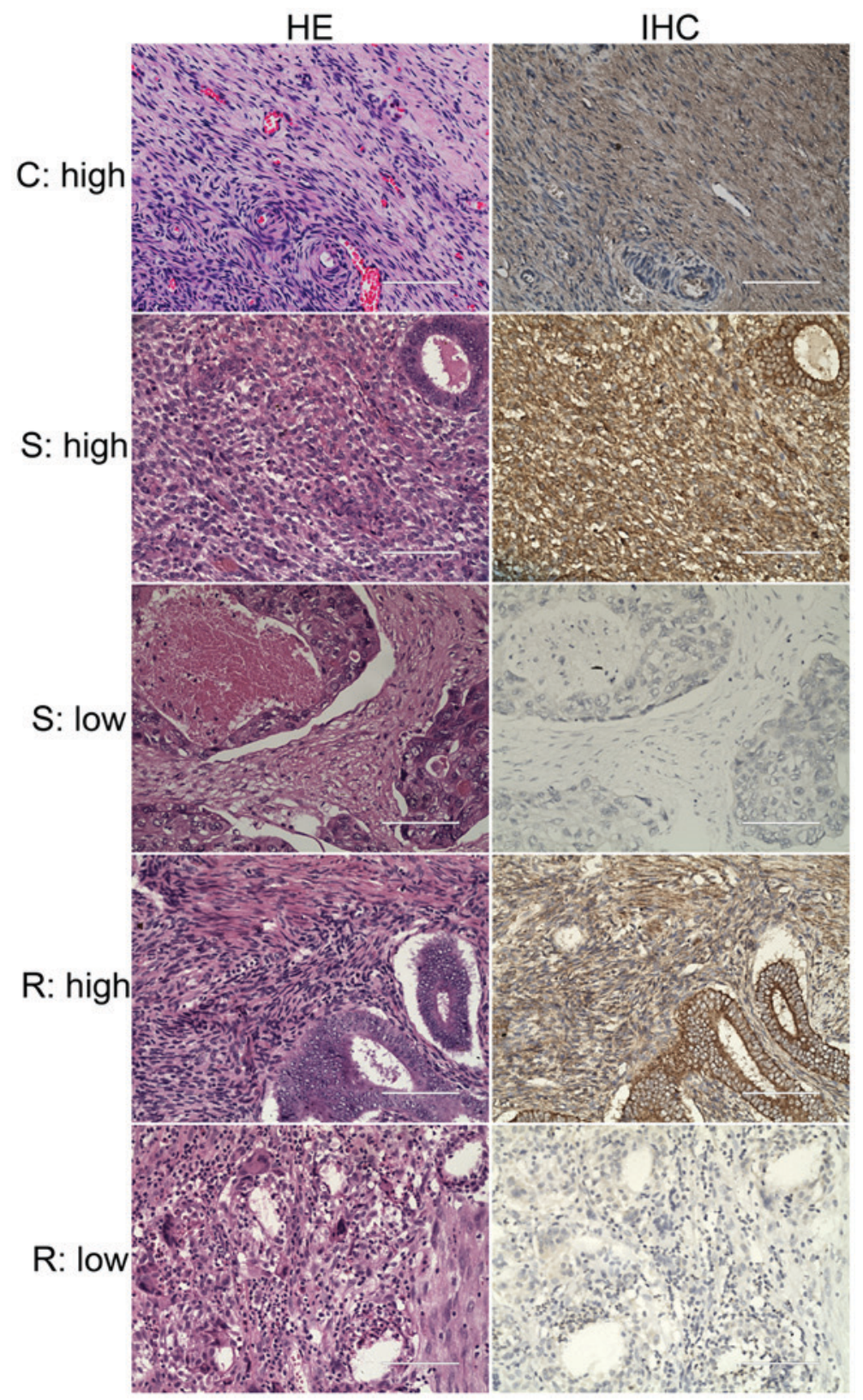

Figure 2. IHC analysis of KCNN3 protein expression in ovarian cancer tissues. A total of two serial sections from the same paraffin-embedded block of patients with ovarian cancer were used for protein detection. Representative staining of KCNN3 high and low expression in normal ovarian tissues; drug-sensitive and resistant tissues are demonstrated. Scale bars, $100 \mu \mathrm{m}$. HE, hematoxylin-eosin staining; IHC, immunohistochemistry; C, normal ovarian tissues as control; S, drug-sensitive; R, drug-resistant; KCNN3, potassium calcium-activated channel subfamily N member 3.

$\mathrm{P}=0.011)$. The percentage of drug-resistant tissues with low expression of KCNN3 was $75 \%$ (18/24 cases), whereas the low expression of the gene in drug-sensitive tissues was only $37 \%$ (10/27 cases; $\mathrm{P}=0.011$; Table $\mathrm{I})$.

Low KCNN3 expression predicts shorter disease-free survival (DFS) and $O S$ in $O C$. KCNN3 expression was analyzed against OC clinical factors, and identified to be associated with prognosis. Lower KCNN3 mRNA expression was significantly associated with shorter DFS in 489 patients with OC in TCGA ovarian cohort (low vs. high groups; average values, $22.630 \pm 1.720$ vs. $35.231 \pm 4.684$; median values, $15.410 \pm 1.049$ vs. $18.040 \pm 1.253$; $\mathrm{P}=0.016$; Fig. $3 \mathrm{~A}$ ), although its association with OS was not significant (low vs. high groups; average values, $49.126 \pm 3.051$ vs. 59.070 44.489 ; median values,
$43.400 \pm 3.858$ vs. $43.890 \pm 2.449 ; \mathrm{P}=0.153$; data not shown). However, lower KCNN3 mRNA expression was significantly associated with poor OS in a large sample of 1,656 patients with OC from the KM Plotter (low vs. high groups; average values, $61.517 \pm 2.608$ vs. $77.324 \pm 4.214$; median values, $44.430 \pm 2.001$ vs. $47.820 \pm 2.564 ; \mathrm{P}=0.014$; Fig. $3 \mathrm{~B}$ ), which included the above 489 patients in TCGA cohort (28). These results were consistent with observations in specimens from 51 patients with OC, in which lower KCNN3 protein expression was significantly associated with poor DFS (low vs. high groups, average values; $16.920 \pm 4.230$ vs. $38.559 \pm 5.764$; median values. $6.000 \pm 0.400$ vs. $47.000 \pm 10.441 ; \mathrm{P}=0.026$; Fig. $3 \mathrm{C}$ ) and $\mathrm{OS}$ (low vs. high groups; average values, $38.950 \pm 5.388$ vs. 68.712 \pm 5.025 ; $\mathrm{P}=0.006$; Fig. 3D). There is no median data for $\mathrm{OS}$ as the mortality rate in this subgroup was $<50 \%$. 

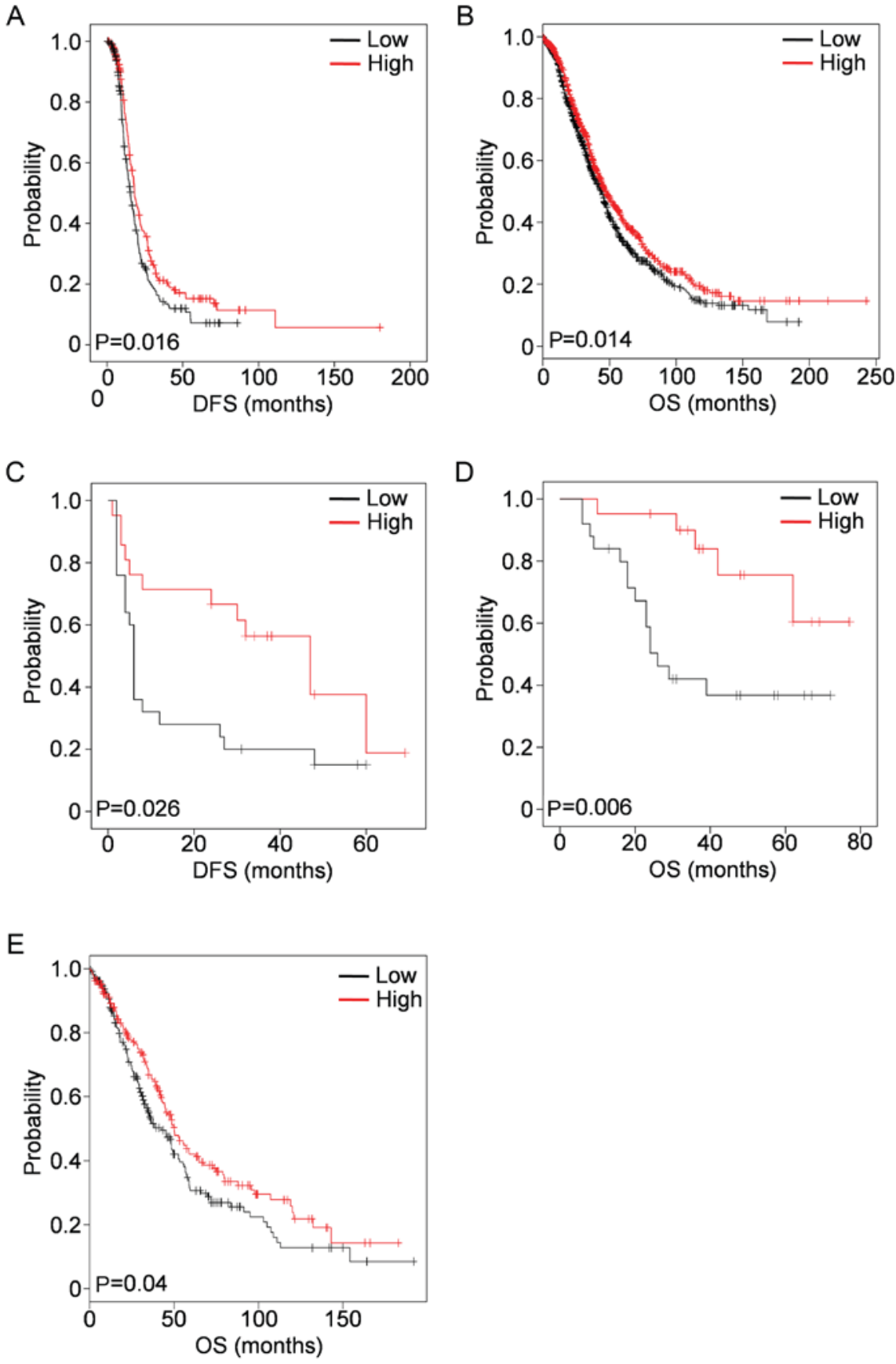

Figure 3. Low KCNN3 expression is associated with DFS and OS in OC, as determined using KM survival plots. (A) Low KCNN3 mRNA expression was associated with shorter DFS in 489 patients with OC (TCGA ovarian cohort). (B) Low KCNN3 mRNA expression (probe: 205903_s_at) was associated with shorter OS in 1,656 patients (data from KM Plotter). Low KCNN3 protein expression was associated with (C) shorter OS and (D) DFS in 51 OC specimens. (E) Low KCNN3 mRNA expression was associated with shorter OS in 395 patients with OC whose CA 125 expression levels were in the lowest quartile (data from KM Plotter). mRNA expression values were dichotomized into high and low, using the median as a cutoff. Protein expression values were dichotomized into high and low, according to slide immunostaining scores. KCNN3, potassium calcium-activated channel subfamily N member 3; DFS, disease-free survival; OS, overall survival; OC, ovarian cancer; KM, Kaplan-Meier; CA 125, cancer antigen 125.

A low expression level of KCNN3 protein in the subgroup of patients with OC with high expression levels of mucin-16 [cancer antigen (CA) 125] ( $\geq 400 \mu 1 / \mathrm{ml})$ was additionally observed, compared with a higher KCNN3 expression level in patients with low expression levels of CA $125(<400 \mu \mathrm{l} / \mathrm{ml}$; Table I). Of these 395 patients with OC who had low CA 125 expression levels (in the lowest quartile), low KCNN3 expression was notably associated with shorter OS in the KM Plotter cohort (Fig. 3E). In addition, low KCNN3 expression was significantly associated with higher histological grade
(Grade III) in the 51 OC specimens from the lab collection, although no significant association was detected between KCNN3 and tumor stage (Table I).

Bioinformatics analyses suggest that KCNN3 mediates drug resistance. Bioinformatics approaches were performed, including protein interaction and text mining, to predict the function of KCNN3 in OC drug resistance. The search terms 'KCNN3', 'OC' and 'drug resistance (DR)' were significantly associated with 51 drugs (e.g. cisplatin, oxaliplatin and 
A
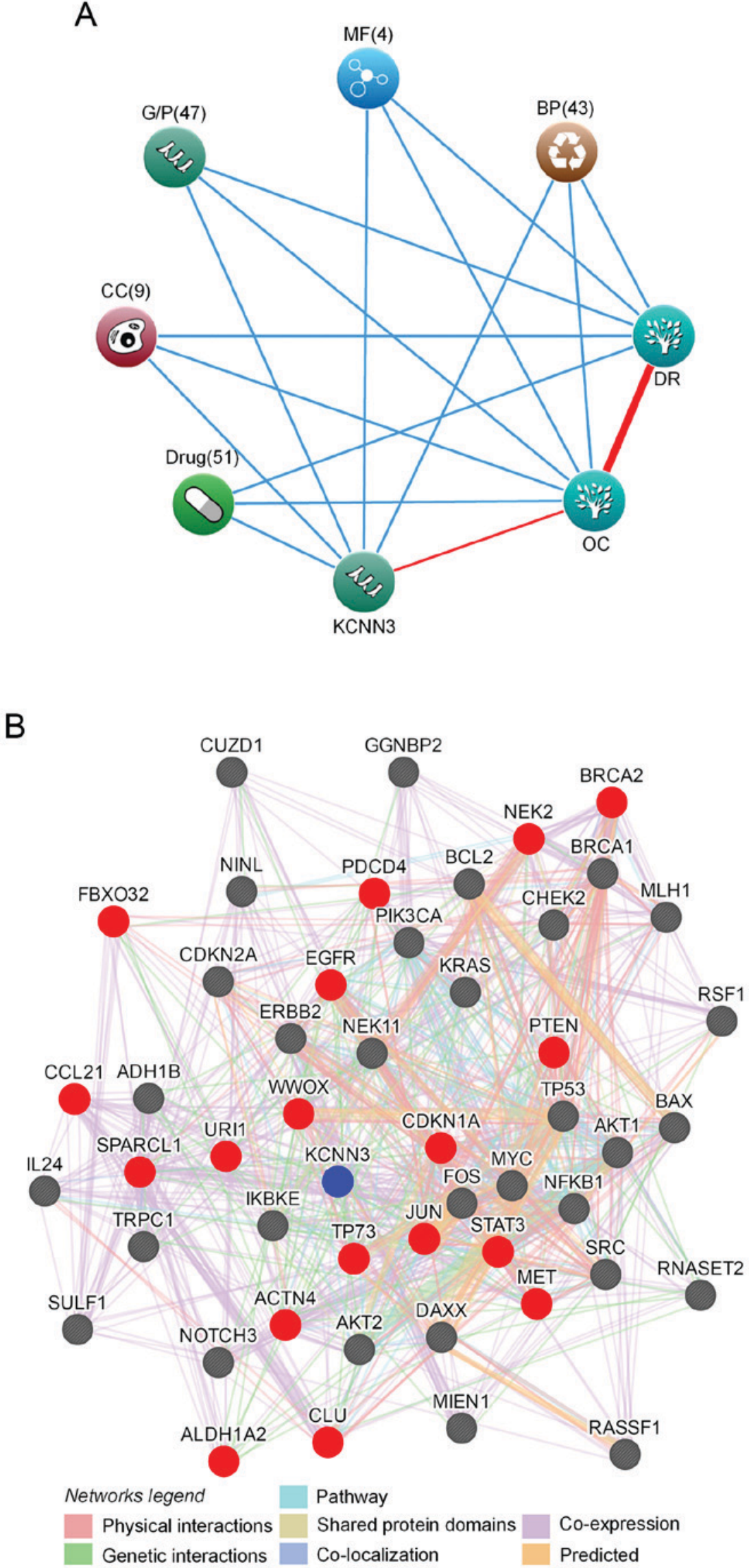

Figure 4. Bioinformatics analyses of associations between KCNN3 and drug resistance in OC. (A) KCNN3 associations with drug resistance and OC, as determined by text mining using Coremine Medical. The input terms were 'KCNN3', 'drug resistance' and 'ovarian cancer'. (B) A protein interaction network of KCNN3 with 49 drug resistance-associated proteins in OC, as generated using GeneMANIA. Red and grey circles represent target proteins that interact with KCNN3 directly and indirectly, respectively. KCNN3, potassium calcium-activated channel subfamily N member 3; OC, ovarian cancer; DR, drug resistance; $\mathrm{BP}$, biological process; MF, molecular function; G/P, genes and proteins; CC, cellular component. 
A

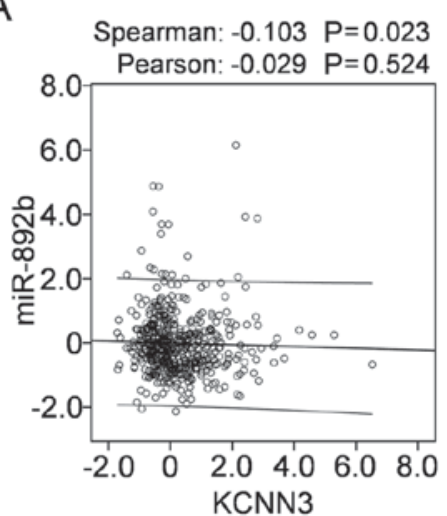

B

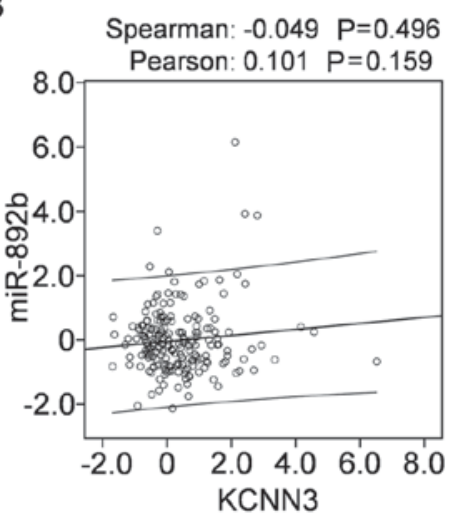

C

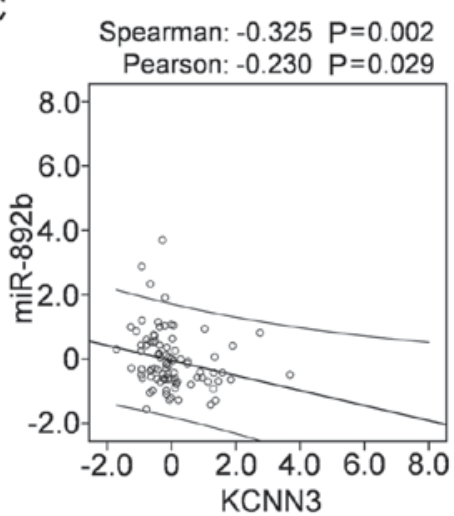

Figure 5. Correlations between miR-892b and KCNN3 expression in 489 OC tissues from TCGA cohort downloaded from cBioPortal. Correlations between miR-892b and KCNN3 expression in (A) 489 OC tissues, (B) 197 platinum-sensitive tissues and (C) 90 platinum-resistant tissues. Correlations between miR and gene expression were analyzed using bivariate correlations. miR, microRNA; KCNN3, potassium calcium-activated channel subfamily N member 3; OC, ovarian cancer; TCGA, The Cancer Genome Atlas.

doxorubicin), 47 genes and proteins (including, TP53, JUN and CD34), 43 biological processes (including, 'apoptosis', 'DNA repair' and 'cell cycle'), nine cellular components and four molecular functions (Fig. 4A). Possible networks of protein or gene interactions with KCNN3 included 49 gene or gene products associated with drug-resistance in OC, which further explained its association with drug resistance. These genes/gene products included 25 oncogenes (35); URI1, STAT3, SRC, RSF1, PIK3CA, NOTCH3, NINL, NFKB1, MYC, MIEN1, MET, KRAS, JUN, IKBKE, FOS, ERBB2, EGFR, DAXX, CUZD1, CLU, BCL2, BAX, AKT2, AKT1 and ACTN4 and 15 tumor suppressors (36) including BRCA1, BRCA2, CHEK2, FBXO32, MLH1, SULF1, IL24, CDKN2A, CDKN1A, TP53, TP73, PDCD4, PTEN, RASSF1 and WWOX, as well as 9 other genes, including CCL21 and SPARCL1 (37), GGNBP2 and RNASET2 (38), NEK2 (39), NEK11 (40), ALDH1A2 and ADH1B (41) and TRPC1 (42). KCNN3 directly interacted with 18 of these genes or gene products, and exhibited indirect interactions with the rest (Fig. 4B). As there were associations between KCNN3 and a wide range of drugs, genes/proteins, biological processes, cellular components and molecular functions with known roles in OC and drug resistance (Fig. 4), it was concluded that KCNN3 expression possibly affects drug resistance in $\mathrm{OC}$.

KCNN3 expression is potentially regulated by $\mathrm{miR}-892 \mathrm{~b}$. To investigate the possible mechanism that mediates KCNN3 expression in OC, mRNA-miR prediction was conducted using the miRSystem, which predicted 35 miRNAs that potentially target KCNN3. Of these, 24 with expression data available in TCGA were downloaded from cBioportal, from which correlations were analyzed between miRNA expression and KCNN3 mRNA expression in 489 OC tissues. Among the 24 miRNAs, only the expression of miR-892b was negatively correlated with KCNN3 mRNA expression in the 489 OC tissues when determined using Spearman's correlation (Fig. 5A; $\mathrm{P}<0.05$ ); however, not when determined using Pearson's $\chi^{2}$ test (Fig. 5A; P>0.05). In 197 platinum-sensitive tissues of the 489 OC tissues, miR-892b was not correlated with KCNN3 (Fig. 5B); however, they were significantly and negatively correlated in 90 platinum-resistant tissues of the
489 OC tissues (Fig. 5C; $\mathrm{P}<0.05$ ). The present results support the possibility that miR-892b targets KCNN3 and contributes to its downregulation in $\mathrm{OC}$, particularly in platinum-resistant tissues.

DNA methylation with KCNN3 mRNA expression levels in 489 OC tissues (including 197 sensitive tissues and 90 resistant tissues) was additionally analyzed; however, no correlation was observed, although DNA methylation of KCNN3 was negatively correlated with mRNA expression (data not shown).

\section{Discussion}

Novel technologies have led to an increase in the volume and diversity of large-scale public data (43), which are a vital pillar of open science and a key enabler of reproducibility and novel discoveries (44). Reuse of public data may potentially answer questions beyond those originally envisioned (45), and provide a systems-level approach to predicting treatment response and disease progression, and to developing precision therapies $(43,46)$. Computational approaches based on these public datasets may additionally facilitate more rapid annotation of protein function and guide laboratory experiments (47). In the present study, microarrays and associated clinical data retrieved from Oncomine, TCGA and KM Plotter were used to identify genes associated with prognosis and drug resistance in OC.

It was identified that KCNN3 was significantly lower in OC tissues compared with normal controls, in agreement with the two independent microarrays, Yoshihara ovarian statistics and TCGA ovarian cohort. This result was consistent with findings that KCNN3 was significantly downregulated in $\geq 10$ tumor types and upregulated in only three different tumors. Further analyses based on TCGA cohort indicated significantly lower KCNN3 expression in drug-resistant OC tissues, which was supported by experiments conducted with 51 OC specimens. Low KCNN3 expression in OC, particularly in drug-resistant tissues, appears to be regulated by miR-892, which has been demonstrated to affect cancer growth, migration, invasion, metastasis and angiogenesis $(48,49)$.

Significantly lower expression of $\mathrm{KCNN} 3$ in $\mathrm{OC}$ and drug-resistant $\mathrm{OC}$ suggests that $\mathrm{KCNN} 3$ mediates 
cancer progression and drug resistance. This hypothesis is supported by bioinformatics analyses, including text mining and protein interaction analyses, and is consistent with a previous study, in which KCNN3 was predicted to be one of 1,298 genes that contribute to drug resistance in OC (50). A previous study demonstrated that KCNN3 together with the TRPC1 and orai-1 complex regulates SOCE-dependent colon cancer cell migration (21). Specifically, acquisition of drug resistance in multiple myeloma is associated with the suppression of inositol 1,4,5-triphosphate receptor type 1, phospholipase $\mathrm{C}$, transient receptor potential cation channel subfamily M member 7 and TRPC1 expression, and reducing the expression of TRPC1 markedly inhibits drug-induced cell death (51). It was observed that decreased expression of TRPC1 is associated with drug resistance in OC (42), and the protein interacts with $\mathrm{KCNN} 3$. Thus, it was concluded that low expression of KCNN3 may contribute to drug resistance via interactions with TRPC1, through inhibition of drug induced cell death.

Downregulation of KCNN3 predicted worse DFS and OS in 51 patients with $\mathrm{OC}$, and consistently predicted worse DFS and OS in 489 and 1,656 patients, respectively, suggesting that it may be a marker for prognosis in $\mathrm{OC}$, in particular for OS. Low KCNN3 expression was notably associated with decreased OS in 395 patients with OC with CA 125 expression levels in the lowest quartile. The downregulation of KCNN3 was associated with higher serum CA $125(\geq 400 \mu \mathrm{l} / \mathrm{ml})$; whereas, KCNN3 upregulation was associated with lower serum CA $125(<400 \mu \mathrm{l} / \mathrm{ml})$, thus it was concluded that the gene may be used to predict OS among patients whose serum CA 125 is $<400 \mu 1 / \mathrm{ml}$.

In conclusion, the present study reported for the first time, to the best of the authors' knowledge, the associations between $\mathrm{KCNN} 3$ and drug resistance and prognosis in $\mathrm{OC}$, which indicate that $\mathrm{KCNN} 3$ is a potential therapeutic target and prognostic marker in the treatment of OC. Further in vitro and in vivo studies are required to validate and clarify the present results.

\section{Acknowledgements}

The authors would like to thank Mrs Marla Brunker, from Liwen Bianji, Edanz Group China`www.liwenbianji.cn/ac), for editing the English text of a draft of this manuscript.

\section{Funding}

The present study was supported by National Natural Science Foundation of China (grant nos. 81460397, 81660606 and 81302283), China Postdoctoral Science Foundation (grant nos. 2014M552535XB and 2014M552291), and Natural Science Foundation of Guangxi (grant nos. 2015GXNSFAA139151, 2014GXNSFBA118155，2015GXNSFBA139115 and 2014GXNSFCA118010).

\section{Availability of data and materials}

The datasets used and/or analyzed during the current study are available from the corresponding author on reasonable request.

\section{Authors' contributions}

FY designed the study. XL performed bioinformatics analyses and data mining. LW and BZ collected samples and clinical data. XC and CD performed immunohistochemical analysis. XL and FY wrote the manuscript. All authors read and approved the final manuscript.

\section{Ethics approval and consent to participate}

The present study was approved by The Ethics Committee of Guangxi Medical University (Nanning, China) with the 1964 Helsinki declaration and its later ethical standards. Informed consent was obtained from all individual participants included in the present study.

\section{Consent for publication}

Not applicable.

\section{Competing interests}

The authors declare that they have no competing interests.

\section{References}

1. Siegel RL, Miller KD and Jemal A: Cancer statistics, 2017. CA Cancer J Clin 67: 7-30, 2017.

2. Chen W, Zheng R, Baade PD, Zhang S, Zeng H, Bray F, Jemal A, $\mathrm{Yu}$ XQ and He J: Cancer statistics in China, 2015. CA Cancer J Clin 66: 115-132, 2016.

3. Cooke SL and Brenton JD: Evolution of platinum resistance in high-grade serous ovarian cancer. Lancet Oncol 12: 1169-1174, 2011.

4. Miller DS, Blessing JA, Krasner CN, Mannel RS, Hanjani P, Pearl ML, Waggoner SE and Boardman CH: Phase II evaluation of pemetrexed in the treatment of recurrent or persistent platinum-resistant ovarian or primary peritoneal carcinoma: A study of the Gynecologic Oncology Group. J Clin Oncol 27: 2686-2691, 2009.

5. Pfisterer J and Ledermann JA: Management of platinum-sensitive recurrent ovarian cancer. Semin Oncol 33 (2 Suppl): S12-S16, 2006.

6. Siegel R, Ma J, Zou Z and Jemal A: Cancer statistics, 2014. CA Cancer J Clin 64: 9-29, 2014.

7. Holohan C, Van Schaeybroeck S, Longley DB and Johnston PG: Cancer drug resistance: An evolving paradigm. Nat Rev Cancer 13: 714-726, 2013.

8. Arcangeli A, Crociani O, Lastraioli E, Masi A, Pillozzi S and Becchetti A: Targeting ion channels in cancer: A novel frontier in antineoplastic therapy. Curr Med Chem 16: 66-93, 2009.

9. Cuddapah VA and Sontheimer H: Ion channels and transporters [corrected] in cancer. 2. Ion channels and the control of cancer cell migration. Am J Physiol Cell Physiol 301: C541-C549, 2011.

10. Prevarskaya N, Skryma R and Shuba Y: Ion channels and the hallmarks of cancer. Trends Mol Med 16: 107-121, 2010

11. D'Amico M, Gasparoli L and Arcangeli A: Potassium channels: Novel emerging biomarkers and targets for therapy in cancer. Recent Pat Anticancer Drug Discov 8: 53-65, 2013.

12. Pardo LA and Stühmer W: The roles of $\mathrm{K}(+)$ channels in cancer. Nat Rev Cancer 14: 39-48, 2014.

13. Innamaa A, Jackson L, Asher V, Van Shalkwyk G, Warren A, Hay D, Bali A, Sowter H and Khan R: Expression and prognostic significance of the oncogenic K2P potassium channel KCNK9 (TASK-3) in ovarian carcinoma. Anticancer Res 33: 1401-1408, 2013.

14. Asher V, Khan R, Warren A, Shaw R, Schalkwyk GV, Bali A and Sowter HM: The Eag potassium channel as a new prognostic marker in ovarian cancer. Diagn Pathol 5: 78, 2010. 
15. Cicek MS, Koestler DC, Fridley BL, Kalli KR, Armasu SM, Larson MC, Wang C, Winham SJ, Vierkant RA, Rider DN, et al: Epigenome-wide ovarian cancer analysis identifies a methylation profile differentiating clear-cell histology with epigenetic silencing of the HERG K ${ }^{+}$channel. Hum Mol Genet 22: 3038-3047, 2013.

16. Pillozzi S, Masselli M, De Lorenzo E, Accordi B, Cilia E, Crociani O, Amedei A, Veltroni M, D'Amico M, Basso G, et al: Chemotherapy resistance in acute lymphoblastic leukemia requires hERG1 channels and is overcome by hERG1 blockers. Blood 117: 902-914, 2011

17. Köhler M, Hirschberg B, Bond CT, Kinzie JM, Marrion NV, Maylie J and Adelman JP: Small-conductance, calcium-activated potassium channels from mammalian brain. Science 273: 1709-1714, 1996.

18. Chantome A, Girault A, Potier M, Collin C, Vaudin P, Pagès JC, Vandier C and Joulin V: KCa2.3 channel-dependent hyperpolarization increases melanoma cell motility. Exp Cell Res 315: 3620-3630, 2009.

19. Potier M, Joulin V, Roger S, Besson P, Jourdan ML, Leguennec JY, Bougnoux P and Vandier C: Identification of SK3 channel as a new mediator of breast cancer cell migration. Mol Cancer Ther 5: 2946-2953, 2006.

20. Jelassi B, Chantome A, Alcaraz-Pérez F, Baroja-Mazo A, Cayuela ML, Pelegrin P, Surprenant A and Roger S: P2X(7) receptor activation enhances SK3 channels- and cystein cathepsin-dependent cancer cells invasiveness. Oncogene 30: $2108-2122,2011$

21. Gueguinou M, Harnois T, Crottes D, Uguen A, Deliot N, Gambade A, Chantôme A, Haelters JP, Jaffrès PA, Jourdan ML, et al: SK3/TRPC1/Orail complex regulates SOCE-dependent colon cancer cell migration: A novel opportunity to modulate anti-EGFR mAb action by the alkyl-lipid Ohmline. Oncotarget 7: 36168-36184, 2016.

22. Li X, Pennisi A, Zhan F, Sawyer JR, Shaughnessy JD and Yaccoby S: Establishment and exploitation of hyperdiploid and non-hyperdiploid human myeloma cell lines. Br J Haematol 138 802-811, 2007.

23. Rhodes DR, Kalyana-Sundaram S, Mahavisno V, Varambally R, Yu J, Briggs BB, Barrette TR, Anstet MJ, Kincead-Beal C, Kulkarni P, et al: Oncomine 3.0: Genes, pathways, and networks in a collection of 18,000 cancer gene expression profiles Neoplasia 9: 166-180, 2007.

24. Rhodes DR, Yu J, Shanker K, Deshpande N, Varambally R, Ghosh D, Barrette T, Pandey A and Chinnaiyan AM: ONCOMINE: A cancer microarray database and integrated data-mining platform. Neoplasia 6: 1-6, 2004.

25. Cancer Genome Atlas Research Network: Integrated genomic analyses of ovarian carcinoma. Nature 474: 609-615, 2011.

26. Cerami E, Gao J, Dogrusoz U, Gross BE, Sumer SO, Aksoy BA Jacobsen A, Byrne CJ, Heuer ML, Larsson E, et al: The cBio cancer genomics portal: An open platform for exploring multidimensional cancer genomics data. Cancer Discov 2: 401-404, 2012

27. Gao J, Aksoy BA, Dogrusoz U, Dresdner G, Gross B, Sumer SO, Sun Y, Jacobsen A, Sinha R, Larsson E, et al: Integrative analysis of complex cancer genomics and clinical profiles using the cBioPortal. Sci Signal 6: pl1, 2013.

28. Gyorffy B, Lánczky A and Szállási Z: Implementing an online tool for genome-wide validation of survival-associated biomarkers in ovarian-cancer using microarray data from 1287 patients. Endocr Relat Cancer 19: 197-208, 2012.

29. Remmele W and Stegner HE: Recommendation for uniform definition of an immunoreactive score (IRS) for immunohistochemical estrogen receptor detection (ER-ICA) in breast cancer tissue. Pathologe 8: 138-140, 1987.

30. Jenssen TK, Laegreid A, Komorowski J and Hovig E: A literature network of human genes for high-throughput analysis of gene expression. Nat Genet 28: 21-28, 2001.

31. Mostafavi S, Ray D, Warde-Farley D, Grouios C and Morris Q: GeneMANIA: A real-time multiple association network integration algorithm for predicting gene function. Genome Biol 9 (Suppl 1): S4, 2008.

32. Warde-Farley D, Donaldson SL, Comes O, Zuberi K, Badrawi R, Chao P, Franz M, Grouios C, Kazi F, Lopes CT, et al: The GeneMANIA prediction server: Biological network integration for gene prioritization and predicting gene function. Nucleic Acids Res 38: W214-W220, 2010.
33. Lu TP, Lee CY, Tsai MH, Chiu YC, Hsiao CK, Lai LC and Chuang EY: miRSystem: An integrated system for characterizing enriched functions and pathways of microRNA targets. PLoS One 7: e42390, 2012.

34. Hedditch EL, Gao B, Russell AJ, Lu Y, Emmanuel C, Beesley J, Johnatty SE, Chen X, Harnett P, George J, et al: ABCA transporter gene expression and poor outcome in epithelial ovarian cancer. J Natl Cancer Inst 106: pii: dju149, 2014.

35. Liu X, Gao Y, Lu Y, Zhang J, Li L and Yin F: Oncogenes associated with drug resistance in ovarian cancer. J Cancer Res Clin Oncol 141: 381-395, 2015.

36. Yin F, Liu X, Li D, Wang Q, Zhang W and Li L: Tumor suppressor genes associated with drug resistance in ovarian cancer (review). Oncol Rep 30: 3-10, 2013.

37. Yin F, Liu X, Li D, Wang Q, Zhang W and Li L: Bioinformatic analysis of chemokine (C-C motif) ligand 21 and SPARC-like protein 1 revealing their associations with drug resistance in ovarian cancer. Int J Oncol 42: 1305-1316, 2013.

38. Yin F, Liu L, Liu X, Li G, Zheng L, Li D, Wang Q, Zhang W and Li L: Downregulation of tumor suppressor gene ribonuclease T2 and gametogenetin binding protein 2 is associated with drug resistance in ovarian cancer. Oncol Rep 32: 362-372, 2014.

39. Liu X, Gao Y, Lu Y, Zhang J, Li L and Yin F: Upregulation of NEK2 is associated with drug resistance in ovarian cancer. Oncol Rep 31: 745-754, 2014.

40. Liu X, Gao Y, Lu Y, Zhang J, Li L and Yin F: Downregulation of NEK11 is associated with drug resistance in ovarian cancer. Int J Oncol 45: 1266-1274, 2014.

41. Liu X, Gao Y, Zhao B, Li X, Lu Y, Zhang J, Li D, Li L and Yin F: Discovery of microarray-identified genes associated with ovarian cancer progression. Int J Oncol 46: 2467-2478, 2015.

42. Liu X,Zou J, Su J, Lu Y, Zhang J, Li L and Yin F: Downregulation of transient receptor potential cation channel, subfamily $\mathrm{C}$, member 1 contributes to drug resistance and high histological grade in ovarian cancer. Int J Oncol 48: 243-252, 2016.

43. Sparks R, Lau WW and Tsang JS: Expanding the immunology toolbox: Embracing public-data reuse and crowdsourcing. Immunity 45: 1191-1204, 2016.

44. Grechkin M, Poon H and Howe B: Wide-Open: Accelerating public data release by automating detection of overdue datasets. PLoS Biol 15: e2002477, 2017.

45. Rung $\mathrm{J}$ and Brazma A: Reuse of public genome-wide gene expression data. Nat Rev Genet 14: 89-99, 2013.

46. Kannan L, Ramos M, Re A, El-Hachem N, Safikhani Z, Gendoo DM, Davis S, Gomez-Cabrero D, Castelo R, Hansen KD, et al: Public data and open source tools for multi-assay genomic investigation of disease. Brief Bioinform 17: 603-615, 2016.

47. Sharan R, Ulitsky I and Shamir R: Network-based prediction of protein function. Mol Syst Biol 3: 88, 2007.

48. Shin SS, Park SS, Hwang B, Moon B, Kim WT, Kim WJ and Moon SK: MicroRNA-892b influences proliferation, migration and invasion of bladder cancer cells by mediating the p19ARF/cyclin D1/CDK6 and Sp-1/MMP-9 pathways. Oncol Rep 36: 2313-2320, 2016.

49. Jiang L, Yu L, Zhang X, Lei F, Wang L, Liu X, Wu S, Zhu J, Wu G, Cao L, et al: miR-892b silencing activates NF- $\mathrm{BB}$ and promotes aggressiveness in breast cancer. Cancer Res 76: 1101-1111, 2016.

50. Lloyd KL, Cree IA and Savage RS: Prediction of resistance to chemotherapy in ovarian cancer: A systematic review. BMC Cancer 15: 117, 2015.

51. Emmons MF, Anreddy N, Cuevas J, Steinberger K, Yang S, McLaughlin M, Silva A and Hazlehurst LA: MTI-101 treatment inducing activation of Stim 1 and TRPC1 expression is a determinant of response in multiple myeloma. Sci Rep 2: 7, 2017.

This work is licensed under a Creative Commons Attribution-NonCommercial-NoDerivatives 4.0 International (CC BY-NC-ND 4.0) License. 